\title{
Young People's Use of Online Social Networking Sites :a Uses and Gratifications Perspective
}

\author{
Aine Dunne \\ Technological University Dublin, aine.dunne@tudublin.ie \\ Margaret-Anne Lawlor \\ Technological University Dublin, malawlor@tudublin.ie \\ Jennifer Rowley \\ Manchester Metropolitan University, J.Rowley@mmu.ac.uk
}

Follow this and additional works at: https://arrow.tudublin.ie/buschmarart

Part of the Advertising and Promotion Management Commons, and the Marketing Commons

\section{Recommended Citation}

Dunne, A., Lawlor, M., Rowley, J.: Young People's Use of Online Social Networking Sites - a Uses and Gratifications Perspective. Journal of Research in Interactive Marketing, Vol. 4 Iss: 1, pp.46 - 58. 2010.

This Article is brought to you for free and open access by the School of Marketing at ARROW@TU Dublin. It has been accepted for inclusion in Articles by an authorized administrator of ARROW@TU Dublin. For more information, please contact arrow.admin@tudublin.ie, aisling.coyne@tudublin.ie,gerard.connolly@tudublin.ie.

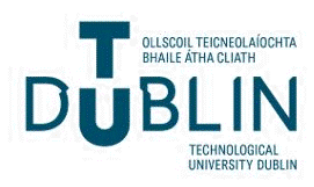




\section{JRIM \\ 4,1}

46

\title{
Young people's use of online social networking sites - a uses and gratifications perspective
}

\author{
Áine Dunne and Margaret-Anne Lawlor \\ Faculty of Business, Dublin Institute of Technology, Dublin, Ireland, and \\ Jennifer Rowley \\ Department of Information and Communications, \\ Manchester Metropolitan University, Manchester, UK
}

\begin{abstract}
Purpose - The purpose of this paper is to explore why young people use and participate in social networking sites (SNSs) with specific reference to Bebo.

Design/methodology/approach - A qualitative approach is employed in this paper with a view to exploring the uses and gratifications ( $\mathrm{U}$ and $\mathrm{G}$ ) that girls aged 12-14 years, both seek and obtain from the Bebo SNS. The research is conducted in a school setting in Ireland.

Findings - The findings indicate that the participants are actively using Bebo for their own personal motives and gratifications in terms of presenting and managing a certain identity and persona in a social context. Furthermore, the relatively impersonal nature of the online environment is seen to especially facilitate the young participants in negotiating the practicalities and difficulties that can arise offline, in terms of forging identities and managing relationships.

Originality/value - $\mathrm{U}$ and $\mathrm{G}$ theory has attracted criticism in terms of a perceived limitation that it only serves to offer lists of reasons as to why audiences attend to the media, and furthermore, a perception that much of the extant $U$ and $G$ research has desisted from discerning between gratifications sought (GS) and gratifications obtained (GO). This paper affirms the appropriateness of the $\mathrm{U}$ and $\mathrm{G}$ theoretical approach in the context of online research. The authors conclude that SNS such as Bebo facilitate the participants in this paper in executing personal aims (for example, identity creation and management) with a view to obtaining certain gratifications (for example, peer acceptance). Therefore, a clear distinction but inextricable link is demonstrated between the GS and GO from participating in SNS.
\end{abstract}

Keywords Social networks, Youth, Consumer behaviour

Paper type Research paper

\section{Introduction}

The online phenomenon of social networking sites (SNSs) has been consistently growing in popularity over the past five years (Boyd and Ellison, 2008). SNSs constitute a form of virtual community, with sites such as Bebo, Facebook and MySpace commanding a vast global following. For example, Facebook and MySpace report in excess of 70 and 50 million active visitors, respectively, on a monthly basis to their sites (Johnson, 2009). However, whilst SNSs are increasingly becoming a focal topic in the communications arena, academia has been slow to keep pace with this continuous growth (Beer, 2008).

Much of the research to date has focused on various aspects of SNSs such as the Marketing

Vol. 4 No. 1, 2010

pp. $46-58$

(C) Emerald Group Publishing Limited 2040-7122

DOI $10.1108 / 17505931011033551$

nature of connecting with friends on these sites (Boyd and Ellison, 2008; Liu, 2008; Tong et al., 2008; Walther et al., 2008; Boyd, 2007), and identity creation and 
management (Boyd and Ellison, 2008; Doster, 2008; Fraser and Dutta, 2008; Boyd, 2007). This exploratory study employs a different approach by considering why young people use and participate in online SNSs. Adopting the uses and gratifications ( $U$ and $G$ ) perspective as the theoretical foundation for this research, the authors investigate the $\mathrm{U}$ and $\mathrm{G}$ that young people aged $12-14$ years, derive from SNSs. The merit of adopting such an approach lies in it facility to provide marketers with an insight into how consumers use and interact with such sites, an aspect particularly relevant to marketers as SNS now represent a valuable marketing communications channel (Fraser and Dutta, 2008). The paper commences by examining the relevance of the $\mathrm{U}$ and $\mathrm{G}$ approach to this research study, before proceeding to consider the nature of SNS. The research methodology underpinning this study is then examined, including the rationale for focusing on young people in this specific age group as the context for this study. Finally, the authors present their research findings and conclusions arising from the study, together with recommendations for future research.

\section{Uses and gratifications theory}

$\mathrm{U}$ and $\mathrm{G}$ theory is the study of the gratifications or benefits that attract and hold audiences to various types of media and the types of content that satisfy their social and psychological needs (O’Donohoe, 1994; Cantril, 1942). Whilst researchers traditionally tended to emphasise the effects of media exposure on audiences, $\mathrm{U}$ and $\mathrm{G}$ theory espouses the need to consider what people do with media (Rubin, 2002; Ruggiero, 2000; Parker and Plank, 2000; O’Donohoe, 1994; Katz, 1959). This theory has been applied to a variety of mass media and media content, with the selection of media type evolving to match the dominant or emerging media of the day. For example, a $\mathrm{U}$ and $\mathrm{G}$ approach has been applied in the context of radio (Herzog, 1944; Cantril and Allport, 1935); various forms of print media, such as newspapers and magazines (Payne et al., 1988; Berelson, 1949) and also in the context of television (Rubin, 1983; Bantz, 1982). A further evolution of $U$ and $G$ research explored its connection with the commercial aspects of media, namely advertising $U$ and $G$ (O'Donohoe, 1994). In recent years, a number of researchers have called for the application of $U$ and $G$ theory in the context of so-called new media, such as the internet (Grant, 2005; Rubin, 2002; Ruggiero, 2000) and mobile phones (Grant and O’Donohoe, 2007).

Rubin (2002) notes that $U$ and $G$ research has tended to focus on one of six major topical areas. These areas include; linking the media-use motives with media attitudes and behaviours, comparing motivations across media forms, examining the different social and psychological circumstances of media use, evaluating the link or indeed difference between gratifications sought (GS) and gratifications obtained (GO), exploring whether variations in backgrounds affect behaviour and attributes and finally, consideration of the methods, reliability and validity of measuring motivation (Rubin, 2002). Of these six areas, the concept of GS versus GO has been relatively neglected (Rubin, 2002), a point to which we will return later in this paper. However, the $U$ and $G$ perspective has also attracted some criticism. One such issue relates to the methodology employed when researching $\mathrm{U}$ and $\mathrm{G}$, and herein, one concern relates to a perceived over-reliance on respondents using self-reporting to generate data (Severin and Tankard, 1988). Additionally, O'Donohoe (1994) acknowledges that U and G theory has been criticised on the basis of a perception that it often does little more than
Young people's use of online SNSs 
JRIM 4,1 generate lists of reasons as to why audiences engage with media. A further criticism is that it presupposes an active audience who is according full attention to the media, which is not always the case (Lometti et al., 1977). Finally, a recurrent theme in the literature is that $\mathrm{U}$ and $\mathrm{G}$ research often desists from discerning between GS and GO (Ruggiero, 2000; Palmgreen et al., 1981).

Notwithstanding these criticisms, researchers such as Rubin (2002) and Ruggiero (2000) note that the emergence of new media forms and in particular, the internet, may have revived and indeed rejuvenated $U$ and $G$ theory. The internet as a mass media form especially lends itself to a $\mathrm{U}$ and $\mathrm{G}$ approach, in part due to its interactive nature (Grant, 2005; Rubin, 2002; Ruggiero, 2000). In this respect, Ruggiero (2000) identifies that concepts to be considered in an internet context, such as activity and interactivity, the nature of the online audience and asynchroneity (the storing of information for consumption at another point in time) need to be reassessed. Williams et al. (1988) also highlight the facility of demassification, namely the control and customisation that the online environment offers the user. As such, the internet and more specifically SNS, constitute newer media formats, with their own defining characteristics, which are ripe for examination under the theoretical lens of $\mathrm{U}$ and $\mathrm{G}$ theory.

\section{Online social networking sites}

SNSs are a form of virtual community, with sites such as Bebo, Facebook and MySpace attracting millions of users world wide, many of whom have integrated the uses of these sites into their daily routines. These sites are based on the premise of relationship creation and maintenance, either with existing members of a social circle or connecting people with similar or shared interests (Boyd and Ellison, 2008). Finin et al. (2005, p. 419) define a social network as an "explicit representation of the relationship between individuals and groups in the community". Elsewhere, Raacke and Bonds-Raacke (2008) indicate that social networks provide a virtual platform where people of similar interests may gather to communicate, share and discuss ideas. From a marketing communications perspective, popular SNS such as Bebo and Facebook constitute brands in their own right and offer marketers access to substantial information about site members. Furthermore, SNS offer marketers the facility for engaging in two-way communication with members in terms of personalised messages and content. However, it is argued that an effective business model in terms of the commercial leveraging of SNS continues to elude marketers.

The social network profile is the focal point of one's social networking existence. Each profile page is unique to the owner and allows its purveyor to literally "type oneself into being" (Sunden, 2003, p. 3). Each member is encouraged to upload their personal profile photograph and share a range of personal information such as where they go to school and details about their personal tastes, such as favourite movies and music (Boyd, 2007). As users have total control over the content that they choose to share and the applications they place on their pages, they can, and usually do, opt to portray themselves in the most positive light. In essence, this means that a user can aspire to an ideal-self through his/her SNS profile. Aside from the inclusion of personal details and photographs, there are two further main components of the social networking profile friends and comments (Boyd, 2007). Profiles offer a facility for communication and interaction between members, usually in the form of a comments section. Friends also play a fundamental role in the composition of SNSs. On joining a SNS, users are 
encouraged to identify others with whom they wish to form relationships. Once the connection is made, the relationship will be visually represented on each user's profile page, under the friends section, within which there is a facility to nominate one's top or best $8,12,16$ or 20 friends, to be listed as such on the user's main profile page (Boyd, 2007). The practice of selecting and displaying one's top friends is referred to by Boyd and Ellison (2008, p. 213) as "public displays of connection" and is often used to provide a real statement about who the person is and the company they keep (Tong et al., 2008; Liu, 2008; Boyd, 2007). Research to date in this area has focused overwhelmingly on one's profile page, primarily regarding how people portray themselves through their profile page and how they connect with friends and acquaintances via the network (Boyd and Ellison, 2008; Tong et al., 2008; Liu, 2008; Boyd, 2007). In this study, the authors examine two uses that young people have for these sites. First, the gratifications or benefits that are being sought (GS) by using these SNSs, and second the gratifications that are in turn being obtained (GO) through the use of these sites.

\section{Research methodology}

The aim of this paper is to explore the $U$ and $G$ that young people, specifically girls, aged 12-14 years, derive from online SNSs. The first research objective guiding this study was to explore the girls' usage of the internet and more specifically SNSs, with the second research objective related to the examination of the reasons for this behaviour. The 12-14 age group is a relevant focus for this research given its immersion from an early age in the online environment (Andersen et al., 2007). It is for this reason that Fraser and Dutta (2008) refer to this grouping as "Generation V" - the virtual generation. Similarly, Samson and Conlon (2006) acknowledge the technological prowess of this age group, referring to this cohort as the connected generation, many of whom have never experienced life without the internet. This segment has not previously been studied from a $U$ and $G$ perspective and the authors feel that research concerning the youth segment, particularly in the context of online $U$ and $G$, would provide valuable insights into this segment's engagement with, and uses of SNS. Furthermore, as the online SNS, Bebo, provides the context for this study, the sample of 12-14 years old was selected on the basis that younger children are not permitted by site regulations to become members of Bebo. The 12-14 year old age group represents the upper cusp of the tween segment, defined by Lindstrom (2004) as constituting children aged between eight and 14 years old. As a segment the tween cohort are traditionally seen to be "in-between" or in a state of transition between childhood and the teenage years and at a period where they are experimenting with their identities, personalities and appearances (Cook and Kaiser, 2004).

A qualitative methodology was employed in this study involving a total of seven, all girl focus groups which were conducted in the setting of an Irish secondary school. A qualitative approach had previously been used across a selection of media and/or advertising U and G studies by Grant and O'Donohoe (2007), Grant (2005), Ritson and Elliott (1999) and O'Donohoe (1994). Each group in this study comprised three to five participants. Similar to the friendship triad employed by Grant and O'Donohoe (2007), the groups were small enough to allow each participant offer their viewpoint, whilst being large enough to allow discourse to develop and flow. In all, 24 girls participated in this research. Cook and Kaiser (2004) note that the tween segment is traditionally accepted as being predominantly female-based in nature particularly as, from a sales
Young people's use of online SNSs 
JRIM

4,1

50

driven perspective, the female tween constitutes a more lucrative niche market that their male counter-parts. This is explained by their consumption of products as fashion, cosmetics and accessories (Cook and Kaiser, 2004). Furthermore, Spicer and Taherreport (2008) identify that teen girls are the predominant drivers of the growth of SNSs vastly outnumbering their male counterparts. The same authors also suggest that girls' consumption of the online environment is different to that of boys, in terms of girls' predisposition to gossip, being more open to communicating, and having more widespread interests.

A semi-structured interviewing format was followed in the conduct of the group discussions. First, the girls were probed about their internet usage in general and web sites they both regularly visited, and liked to visit. They were then probed as to the reasons for this behaviour. The focus groups were recorded with the girls' permission and subsequently transcribed. With regard to data analysis, each transcript was examined and the information collected was then categorised according to the emergent themes. Examples of such themes included identity creation and management, and escapism. These themes emerged from the issues discussed during the focus groups and were also informed by the themes which surfaced in previous research relating to $\mathrm{U}$ and G theory (O'Donohoe, 1994) and SNSs (Boyd, 2007).

A number of important ethical considerations were applied in the conduct of this research, for example with regard to guaranteeing the participants anonymity, negotiation of access to the age group, and the acquisition of written consent from both the participants and their parents. Additionally, the participants' names have been changed for the purpose of anonymity. Furthermore, the research was conducted in a school environment, a safe environment for both the children and the researcher (Banister and Booth, 2005).

\section{Discussion}

Each of the girls, who participated in the focus groups, presented themselves as regular online users. When questioned as to which web sites they frequently visited, the discussions tended to turn quickly to SNS, such as Bebo, Facebook or MySpace, and virtual worlds such as Zwinky. However, SNS became the focal point of the discussions, as initiated by the participants, with an especially strong emphasis being placed on Bebo in particular. As such, this paper focuses on the girls' consumption of the Bebo site.

Throughout the focus group discussions, it became apparent that there was a diverse and wide-ranging variety of reasons why young people visited the Bebo site, which duly led to certain gratifications being obtained from such SNS usage. For example, many of the focus group participants stated that updating their Bebo pages and examining other users' pages allowed them to communicate with others (GS). This in turn facilitated the participants in gaining or maintaining peer acceptance (GO). Table I provides a summary of the primary GS and GO, which emerged from the focus group discussions.

In their discussions as to why they engaged with SNSs, the participants noted a number of purposes that SNS served from their point of view. However, as the discussions progressed, it transpired that the uses of SNS, for example, to communicate with others, also led to certain gratifications being obtained. To this end, the participants offered varying and interesting insights as to the benefits they obtained 
from these sites. For example, a frequently discussed topic that emerged, in the context of GS, was the often-interconnected themes of communication and friending (GS). In this respect, Sophie (aged 13 years) described how she used the site thus:

I use them to chat with friends and keep in contact with my friends. I moved here from England so I find it really helpful to easily keep in touch with all my old friends. I'm an only child as well so when I move, it was only me and my parents so the internet is really a form of connection to my old life.

Although this scenario was given as support to her claim that communicating with friends was her primary use for SNS, Sophie's contribution also indicates how a site such as Bebo facilitates her overall desire to maintain existing relationships (GO). A similar example was given by another participant who noted how she used Bebo for friending purposes having recently moved to Ireland from Eastern Europe: "I use Bebo to talk to my friends. It helped me to make friends easily and feel part of the group" (Anna, 13 years). Clearly, there is a close link here between GS (making friends) and GO (group/peer acceptance). Elsewhere, in the discussion regarding communication with friends, Emma (aged 13 years) noted that SNS, particularly Bebo, facilitated her in the following manner:

I use them to talk with your friends, it's cheaper than texting them, well for me anyway, I don't have to pay for the internet.

As such, Emma's contribution illustrated her rationale for using Bebo and the accompanying reward. The majority of girls also identified using Bebo as a means of escape and the alleviation of boredom (GS). For example, Jane (13 years) stated that she simply uses Bebo "for something to do". This sentiment was echoed by Amanda (13 years) who noted "I go on Bebo just for something to do, like if I'm bored at home". Additionally, many of the participants also highlighted their use of SNS for information seeking (GS) purposes: "to see what is new with everyone" (Becky, 14 years). When asked how the use of Bebo facilitates this, Becky identified that her friends shared new information about themselves and their recent activities by updating various elements of their profile pages, such as the "about me" section, together with the uploading of new photos, videos and new comments. Becky's contribution regarding the sharing and seeking of information through SNSs, reflects Singer's (1998) observation that the internet is capable of empowering the individual both by providing them with the information they require and enabling them to create and share any information.

\begin{tabular}{ll}
\hline Gratifications sought & Gratifications obtained \\
\hline Communication & Portraying one's ideal image \\
Friending & Peer acceptance \\
Identity creation and management & Relationship maintenance \\
Entertainment & Safety from embarrassment and rejection \\
Escapism and alleviation of boredom & Engaging in playground politics \\
Information search &
\end{tabular}

Young people's use of online SNSs 
JRIM

4,1

52

A further and highly popular theme that frequently emerged in relation to GS was that of entertainment (GS), for example: "I really enjoy going onto Bebo, it's fun" (Anne, 13 years). The girls were probed as to the nature of such entertainment, to which Sarah (14 years) elaborated: "I think checking out other people's photos and video clips is great fun, you get a good laugh out of it". Using SNS to interact with boys online, as opposed to the alternative of the more visible offline environment, was also identified by a number of girls, as a popular reason for engaging in sites such as Bebo. Indeed, this particular GS can also be linked with the information searching (GS), communication (GS) and friending (GS). In this manner, participation in the site provided them with safety from embarrassment and rejection (GO): "it's a good way of talking to boys, you can post a comment on their site or ask them to be your friend without being embarrassed or feeling stupid" (Kate, 14 years). This is an example of where the internet, and more specifically SNSs, is seen to offer an advantage over personal communication, in terms of facilitating the initiation of contact between the participants and boys.

As previously noted, while the GS are the explicit reasons that the participants have for using SNS, such as Bebo in the first place, it also emerged that a number of additional needs are being met through the use of such SNS, namely GO. Upon extended discussion on the topic of communication and friending (GS), a number of GO materialised. In addition to the previously mentioned maintenance of existing relationships (GO), another GS from participating in Bebo was that of identity creation which should accordingly facilitate peer acceptance (GO): "you can tell people about yourself, who you are and what you like and make friends that way" (Allison, 13 years). As such, Allison's contribution depicts the link between online GS and GO. By communicating with other Bebo users, Allison can manage the personal information which she makes available on her Bebo page, thus creating a certain identity with a view to achieving peer acceptance. The importance of identity creation and impression management (GS) was also noted in a number of other discussions. For example, Gemma (aged 13 years) asserted: "you can make yourself look good, you know, pick the best picture of yourself, put on a cool skin, show off your coolest friends and just look fun".

Similarly, the importance of presenting a positive self-identity was noted by Anne (aged 13 years): "you will always put up the best photos of yourself, you don't want to make yourself look bad or stupid". Again the clear link between identity creation and management (GS) and the accompanying desire for peer acceptance (GO) is evident in Gemma and Anne's contributions.

The girls' awareness of the opinion of others and indeed their assessment of other users' contributions was also evident elsewhere:

Sometimes you look at people's profile pictures and go "oh my god, what are they at"? Some of the stuff they say about themselves is exaggerated as well, they are trying to make themselves look cool (Suzy, 14 years).

Furthermore, the issue of engaging in playground politics (GO) was raised by a small number of girls in relation to SNS when discussing the aspect of friending. In the following example, Louise indicates how her Bebo web page can be used to signal her dissatisfaction with another user:

[...] you can use Bebo when you're fighting with someone too, like if I'm not talking to someone, I take them off my top friends list or if it's really bad, I delete them totally (Louise, 13 years). 
The link between GS and GO became quite evident with one girl (Stephanie, 14 years) who noted: "I go on Bebo to mainly talk with my friends, I spend hours on it every day", thus identifying purposes such as communication, in terms of talking with friends and escapism, which is alluded to by the duration spent immersed in the world of SNSs on a daily basis. Additionally, this participant's prolonged usage of these sites illustrates how she uses these sites to pass her time and therefore obtains rewards such as entertainment or the alleviation of boredom. However, she proceeded: "I don't actually have my own Bebo site. I use Bebo through my older sister's [aged 19 years] profile. It's better than just having your own". On being probed as to the rationale for this, she explained: "because it's just more fun to use my sister's site. People think that it is my sister that's online". This is a clear example of identity creation and management (GS). It also underscores how SNSs serve to facilitate the user in interacting with others with relative anonymity.

Continuing with this theme, it is important to highlight that the majority of participants were alert to the potential downsides and dangers which may prevail in an online environment:

Sometimes you have to be careful especially if someone you don't know asks you to be their friend on Bebo and you don't know them, you really can't be sure if they are the person in their profile pictures. I mean, you hear stories about young people getting tricked by older people who lie about their age and who they are online (Olivia, 13 years).

As the above discussion has highlighted, much of the rationale offered by the focus group participants for engaging with the Bebo site, that is to say the gratifications they are seeking are often as simple as communication, entertainment or friending. However, the gratifications that are actually being met or obtained from the use of such sites are deeper and more complex. If we consider the example above of Sophie (13 years) who stated she used Bebo for communication and friending having recently moved from England to Ireland. Probing further into her rationale, the researchers found that she was using these sites for relationship maintenance and indeed, rather than simply being a source of entertainment for Sophie, as was the case with a number of the participants, Bebo provided Sophie with an invaluable connection to the life she had left and assisted her in an easier transition into her new life.

\section{Conclusion}

As previously alluded to, SNSs constitute a rapidly growing phenomenon, with sites such as MySpace and Facebook attracting 250,000-300,000 new members on a daily basis (Fraser and Dutta, 2008). However, there is a distinct lack of academic research on the subject (Beer, 2008) and more specifically, there is a meagre body of empirical research pertaining to an exploration of the possible application of $\mathrm{U}$ and $\mathrm{G}$ in an online context. Examples include Grant's (2005) study of young people's relationship with online marketing, and Raacke and Bonds-Raacke's (2008) application of U and G in the context of SNSs.

Ruggiero (2000) posits that two questions, both theoretical and practical, prevail for all $U$ and $G$ researchers. These are: why do users interact in a specific type of mediated communication, and second, what gratifications are obtained from such interaction? In line with this, our study sought to address these questions by examining why young people participate in SNSs and the benefits obtained from this engagement.
Young people's use of online SNSs

53 
JRIM 4,1

54

This research indicates that SNS and specifically in this case, Bebo, play a significant role in the lives of the 12-14 year old girls participating in this study but the reasons they have for engaging in these sites are varied and often quite personal.

Academic research to date has focused primarily on the aspects of friending (Boyd and Ellison, 2008; Tong et al., 2008; Liu, 2008; Boyd, 2007) and identity management (Boyd and Ellison, 2008; Doster, 2008; Fraser and Dutta, 2008; Boyd, 2007), and these elements were also identified in this study as gratifications. However, this research has highlighted a number of additional $\mathrm{U}$ and $\mathrm{G}$ that were sought (GS) from SNS participation including communication, entertainment, escapism and the alleviation of boredom, interaction with the opposite sex, and information searching. On deeper investigation, the participants unveiled numerous underlying GO from the use of SNSs, namely, the portrayal of one's ideal image, peer acceptance, relationship maintenance, safety from embarrassment and rejection, and finally, engagement in playground politics.

A common criticism that is levelled against $U$ and $G$ research is the frequent absence therein to discern between GS and GO (Ruggiero, 2000; Palmgreen et al., 1981). In this study, many of the GS (e.g. identity creation and identity management) were clearly connected to the GO, i.e. the rewards that accrued from such actions (e.g. peer acceptance). More specifically, the girls' personal motives for participating in SNS were demonstrated to be frequently and inextricably linked with social outcomes. For example, maintaining a Bebo page was often viewed as being an opportunity to interact with the opposite sex. A positively viewed outcome of the non-personal nature of the online environment was its ability to offer the participants relative shelter from embarrassment and rejection. Therefore, even if the latter did occur, it did so in the relatively impersonal environment of Bebo where face-to-face and non-verbal communication are absent.

A further criticism of $U$ and $G$ theory is its assumption of an active audience (Lometti et al., 1977). While one could argue over the degree to which a user is active in relation to media such as television or radio, the internet as a media form negates this criticism as, in order to engage with the any form of content on the internet, the audience must be active. In the case of this research, an SNS user is very much part of an active audience from the point at which they log on to the SNS. Activities such as divulging or seeking information, posting comments, sharing one's photographs and videos and connecting with new friends, ensure that the $\mathrm{U}$ and $\mathrm{G}$ application to SNS nullifies a long-standing criticism of U and G theory. Rubin (2002) outlines how the GS and $\mathrm{GO}$ dimensions to $\mathrm{U}$ and $\mathrm{G}$ theory has been ignored by academics for over two decades, and the few studies that have applied this approach, have done so primarily in a quantitative context. In this study, the authors have examined the various GS and GO from the Bebo site, using a qualitative methodology. Indeed, this study has shown that not only can a qualitative methodology be employed to successfully identify GS and GO but also that the link between GS and GO can provide rich and interesting insights into the mindsets of young SNS users.

From a marketer's perspective, this study has outlined how tweens use sites such as Bebo to share information about their lifestyles, interests, tastes and experiences, thus offering valuable insights into the online behaviour of tweens, and also serving to enhance marketers' understanding of the lucrative tween segment. Boyd and Ellison (2008) indicate that SNS provide an opportunity for users to articulate and make visible their social connections. This is not only true in relation to human connections but can 
also be applied to articulating one's connections to or affiliation with brands. As identified previously aspects such as friending and identity management are very important to SNS users. Considering this, understanding how tweens use these sites may be very beneficial to marketers. Whilst the girls in this study did not refer to the presence of brand messages on their Bebo pages or within the site, it is contended that sites such as Bebo facilitate members becoming fans of or indeed become friends with a brand, e.g. a band, movie or television show. This "befriending" of brands is a statement of personal endorsement of this particular brand and in turn this action can provide the brand with very positive electronic word of mouth (eWOM). Unlike tradition offline WOM, eWOM often occurs between consumers with little or no prior relationship and indeed may occur in total anonymity (Lee and Youn, 2009). Therefore, marketers need to be aware of the discussions and interactions, both brand-related and non-brand-related, that tween users are engaging in, by means of social media.

As previously alluded to, the tween consumer is a highly lucrative consumer grouping. However, they are also a group in transition, often trying to distance themselves from the child label but yet not part of teen cohort (Anderson et al., 2007; Samson and Conlon, 2006; Cook and Kaiser, 2004). The tween segment exists in an unstable and fickle culture where they are constantly experimenting with their social identity (Samson and Conlon, 2006; Cook and Kaiser, 2004). In this study, the participants noted that identity creation and management play a major role in their engagement with SNS. Not only can SNS provide tweens with an avenue for experimenting with their social identity, but through brand befriending, it can also provide tweens with an opportunity to develop their commercial identity.

In conclusion, this study has demonstrated how the $U$ and $G$ approach is both appropriate and relevant in the context of the online environment and specifically SNS. This supports the stance of previous researchers who have promoted its application in the context of online-based research (Grant, 2005; Stafford et al., 2004; Rubin, 2002; Ruggiero, 2000). However, this study is not without its limitations. For example, as Bebo proved to be the SNS of choice amongst our sample, discussion and actions primarily focused on this SNS alone. The authors note that a sample comprising a different age grouping may gravitate towards a different SNS and thus have very different experiences to those of our sample. Therefore, future research might consider the $U$ and $G$ that older audiences might seek and obtain from other SNS such as Facebook and MySpace. Furthermore, it became clear in this research that the participants view Bebo, their SNS of choice, as a resource for their own personal and social uses. Therefore, a potential research avenue is to explore SNS users' experiences of, and attitudes towards the marketing and advertising messages that are becoming increasingly prevalent in these sites.

As SNS continue to attract substantial numbers of new and existing members on a daily basis, user motivations for participating in SNS, and the resulting rewards and gratifications, represent fertile ground for further exploration.

\section{References}

Andersen, L., Tufte, B., Rasmussen, J. and Chan, K. (2007), "Tweens and new media in Denmark and Hong Kong", Journal of Consumer Marketing, Vol. 24 No. 6, pp. 340-50.

Banister, E. and Booth, G. (2005), "Exploring innovative methodologies of child-centric consumer research”, Qualitative Market Research, Vol. 8 No. 2, pp. 157-75.
Young people's use of online SNSs 
JRIM

4,1

56

Bantz, C.R. (1982), "Exploring uses and gratifications: a comparison of reported uses of television and reported uses of favourite program type", Communications Research, Vol. 9, pp. 352-79.

Beer, D. (2008), "Social network(ing) sites ... revisiting the story so far: a response to Danah Boyd and Nicole Ellison", Journal of Computer-mediated Communication, Vol. 13 No. 2, pp. 516-29.

Berelson, B. (1949), "What missing the newspaper means", in Lazarsfeld, P.F. and Stanton, F.N. (Eds), Communications Research 1948-1949, Harper, New York, NY, pp. 111-29.

Boyd, D. (2007), "Why youth (heart) social networking sites: the role of networked publics in teenage social life", in Buckingham, D. (Ed.), Youth, Identity and Digital Media, MIT Press, Cambridge, MA, pp. 119-42.

Boyd, D. and Ellison, N. (2008), "Social networking sites: definition, history, and scholarship", Journal of Computer-mediated Communications, Vol. 13 No. 1, pp. 210-30.

Cantril, H. (1942), "Professor quiz, a gratifications study", in Lazarsfeld, P.F. and Stanton, F.N. (Eds), Radio Research 1941, Duell, Sloan and Pearce, New York, NY, pp. 31-45.

Cantril, H. and Allport, G. (1935), The Psychology of Radio, Harper, New York, NY.

Cook, D. and Kaiser, S. (2004), "Betwixt and between: age ambiguity and the sexualization of the female consuming subject”, Journal of Consumer Culture, Vol. 4 No. 2, pp. 203-27.

Doster, L. (2008), "Millennial teens design their social identity via online social networks", Academy of Marketing Conference Proceedings, Aberdeen, July.

Finin, T., Ding, L., Zhou, L. and Joshi, A. (2005), "Social networking on the semantic web", The Learning Organisation, Vol. 12 No. 5, pp. 418-30.

Fraser, M. and Dutta, S. (2008), Throwing Sheep in the Boardroom: How Online Social Networking Will Transform Your Life, Work and World, Wiley, Chichester.

Grant, I. and O'Donohoe, S. (2007), "Why young consumers are not open to mobile marketing communications", International Journal of Advertising, Vol. 26 No. 2, pp. 223-46.

Grant, I.C. (2005), "Young peoples' relationship with online marketing practices: an intrusion too far?", Journal of Marketing Management, Vol. 21 Nos 5/6, pp. 607-23.

Herzog, H. (1944), "What do we really know about daytime serial listeners", in Lazarsfeld, P.F. and Stanton, F.N. (Eds), Radio Research 1941, Duell, Sloan and Pearce, New York, NY, pp. 3-33.

Johnson, S. (2009), "How twitter will change the way we live (in 140 characters or less)", Time Magazine, Vol. 173 No. 23, pp. 28-33.

Katz, E. (1959), "Mass communication research and the study of popular culture: an editorial note on a possible future for this research", Studies in Public Communications, Vol. 2 No. 1, pp. 1-6.

Lee, M. and Youn, S. (2009), "Electronic word of mouth (eWOM): how eWOM platforms influence consumer product judgement", International Journal of Advertising, Vol. 28 No. 3, pp. 473-99.

Lindstrom, M. (2004), "Branding is no longer child's play", Journal of Consumer Marketing, Vol. 21 No. 3, pp. 175-82.

Liu, H. (2008), "Social network profiles as taste performance", Journal of Computer-mediated Communications, Vol. 13 No. 1, pp. 252-75. 
Lometti, G.E., Reeves, B. and Bybee, C.R. (1977), "Investigating the assumptions of uses and gratifications research", Communications Review, Vol. 4, pp. 321-38.

O'Donohoe, S. (1994), “Advertising uses and gratifications”, European Journal of Marketing, Vol. 28 Nos 8/9, pp. 52-75.

Palmgreen, P., Wenner, L.A. and Rayburn, J.D. (1981), "Gratification discrepancies and news programme choice”, Communications Research, Vol. 8, pp. 451-78.

Parker, B.J. and Plank, R.E. (2000), "A uses and gratifications perspective on the internet as a new information source”, American Business Review, Vol. 18 No. 2, pp. 43-50.

Payne, G.A., Severn, J.J. and Dozier, D.M. (1988), "Uses and gratifications motives as indicators of magazine readership", Journalism Quarterly, Vol. 65 No. 4, pp. 909-13.

Raacke, J. and Bonds-Raacke, J. (2008), "MySpace and Facebook: applying the uses and gratifications theory to exploring friend-networking sites", CyberPsychology \& Behaviour, Vol. 11 No. 2, pp. 169-74.

Ritson, M. and Elliott, R. (1999), "The social uses of advertising: an ethnographic study of adolescent advertising audiences", Journal of Consumer Research, Vol. 26 No. 3, pp. 260-77.

Rubin, A.M. (1983), "Television uses and gratifications", Journal of Broadcasting, Vol. 27, pp. 37-51.

Rubin, A.M. (2002), "The uses and gratifications perspective of media effects", in Bryant, J. and Zillmann, D. (Eds), Media Effects: Advances in Theory and Research, 2nd ed., Lawrence Erlbaum Associates, Mahwah, NJ, pp. 525-48.

Ruggiero, T.E. (2000), "Uses and gratifications theory in the 21st century", Mass Communication \& Society, Vol. 3 No. 1, pp. 3-37.

Samson, N. and Conlon, J. (2006), "Marketing to the connected generation", paper presented at The Marketing Research Society Annual Conference, available at: http://warc.com.ditlib. dit.ie/ArticleCenter/Default.asp?CType=A\&AID=WORDSEARCH81430\&Tab=A (accessed 29 July 2009).

Severin, W. and Tankard, J. (1988), Communications Theory, Longman, New York, NY.

Singer, J.R. (1998), "Online journalists: foundations for research into their changing roles", Journal of Computer-mediated Communications, Vol. 4 No. 1, available at: http://jcmc. indiana.edu/vol4/issue1/singer.html (accessed 30 July 2009).

Spicer, K. and Taherreport, A. (2008), "Girls and young women are now the most prolific web users”, The Sunday Times, March 9, available at: http://technology.timesonline.co.uk/tol/ news/tech_and_web/the_web/article3511863.ece (accessed 20 October 2009).

Stafford, T.F., Stafford, M.R. and Schkade, L.L. (2004), "Determining uses and gratifications for the internet”, Decision Sciences, Vol. 35 No. 2, pp. 259-88.

Sunden, J. (2003), Material Virtualities, Peter Lang, New York, NY.

Tong, S., van Der Heide, B., Langwell, L. and Walther, J. (2008), "Too much of a good thing? The relationship between number of friends and interpersonal impressions on Facebook", Journal of Computer-mediated Communication, Vol. 13 No. 3, pp. 531-49.

Walther, J., van Der Heide, B., Kim, S., Westerman, D. and Tong, S. (2008), “The role of friends' appearance and behaviour on evaluations of individuals on Facebook: are we known by the company we keep?", Human Communication Research, Vol. 34 No. 1, pp. $28-49$.

Williams, F., Rice, R.E. and Rogers, E.M. (1988), Research Methods and the New Media, The Free Press, New York, NY.

\section{Young people's use of online SNSs}




\section{JRIM}

4,1

58

\section{About the authors}

Aine Dunne is a $\mathrm{PhD}$ Candidate at the Faculty of Business, Dublin Institute of Technology, Ireland. Her research interests include young people's consumption of the internet and other forms of new media and tweens relationship with online branded environments. She has previously presented competitive papers at the Academy of Marketing Conference 2008, in Aberdeen and the 2009 conference in Leeds. Aine Dunne is the corresponding author and can be contacted at: aine.dunne@dit.ie

Margaret-Anne Lawlor is a Lecturer in Marketing Communications at the Faculty of Business, Dublin Institute of Technology, Ireland. Her research interests include children's interaction with advertising, and young people's consumption of new and emerging media. She has previously published in the European Journal of Marketing, the Journal of Marketing Management, Irish Marketing Review and the Services Industries Journal.

Jennifer Rowley is a Professor of Information and Communications at the Department of Information and Communications, Manchester Metropolitan University. She has authored or acted as co-author of numerous books and journal articles, and refereed conference papers. Her research interests include information and knowledge management, marketing, e-business and teaching and learning, with the core theme of information use, access, user and consumer behaviour and experience.

To purchase reprints of this article please e-mail: reprints@emeraldinsight.com Or visit our web site for further details: www.emeraldinsight.com/reprints 